\title{
O estado actual do problema da hereditariedade
}

Conferencia feita pelo Dr. André Dreyfus no 1.o Congresso Brasileiro de Eugenia 1.0 Assistente de Histologia e Embyrologia da Faculdade de Medicina de São Paulo

Meus Senhores!

U MA comparação entre as theorias biologicas e as theorias physicas ou mesmo chimicas, mostrar-nos-á que emquanto merecem realmente estas ultimas o nome de theorias scientificas, pois permittem deduzir os mais diversos phenomenos relativos a um determinado assumpto de um corpo de principios pouco numerosos, exprimindo suas relações em linguagem mathematica e permittindo prever novos casos, em biologia, até pouco tempo nenhuma concepção geral da mesma ordem era conhecida.

As descobertas de Mendel, conduziram a uma theoria biologica permittindo previsões, que a observação e a experiencia confirmaram.

A importancia theorica e pratica dos problemas hereditarios preoccupou desde sempre philosophos e biologistas. A causa das semelhanças e differenças observaveis entre ascendentes e descendentes, a obtenção de raças animaes ou vegetaes possuindo determinadas propriedades, o problema da determinação dos sexos, a solução do mecanismo da transmissão das doenças hereditarias foram sempre objecto de cogitações para a humanidade. Taes questões, bem como a solução do problema da evolução das especies, representam assumptos que só podem ser resolvidos na medida em que nos tenhamos tornado capazes de dar conta do mecanismo da hereditariedade.

Desde a mais alta antiguidade, existem pois theorias da hereditariedade. Não uma, mas muitas conferencias se- 
riam necessarias se quizessemos passal-as em revista. Lembremos que só para dar conta do mecanismo da determinação dos sexos, que corresponde a um aspecto particular da questão, Drelincourt em 1685 reuniu 262 theorias.

Coube porem ao abbade Gregorio Mendel a gloria de em 1865, estabelecer o mecanismo da transmissão dos caracteres hereditarios. Tal descoberta nenhuma connexão tem com os trabalhos anteriormente feitos e marca o inicio da era scientifica da hereditariedade. Eis porque não ha inconveniente em silenciarmos a respeito de todas as theorias que precederam esse trabalho.

Poder-se-á julgar do merito de Mendel pelas seguintes phrases de T. H. Morgan: "A biologia tem sido e ainda é uma sciencia em grande parte descriptiva e especulativa, Mendel demonstrou com provas experimentaes que a hereditariedade podia ser explicada por um mecanismo simples." "A sciencia alcança sua finalidade quando póde substituir suas primeiras conjecturas por hypotheses verificaveis e resultados prognosticaveis, e foi isto que as leis de Mendel fizeram com a hereditariedade." E Bateson escreve: "Se o trabalho de Mendel tivesse chegado ás mãos de Darwin, podemos estar certos de que a historia do desenvolvimento da philosophia evolucionista teria tido uma forma differente daquella que testemunhamos".

Não nos deteremos na analyse dos motivos que fizeram com que o mais extraordinario trabalho sobre hereditariedade até hoje publicado, permanecesse cerca de 35 annos totalmente desconhecido, morrendo Mendel neste intervallo de tempo sem ter tido o consolo de encontrar um unico biologista que lhe reconhecesse a genialidade. A ausencia de figuras, a aridez resultante do caracter algebrico da demonstração e outras causas apontadas não dão absolutamente conta deste extranho phenomeno. Como é bem sabido 3 sabios europeus trabalhando independentemente uns dos outros: Correns em Tubingen, Tschermak em Vienna, e De Vries em Amsterdam redescobrem em 1900 as famosas leis e a De Vries coube o merito de ter chamado a attenção do mundo scientifico para o maravilhoso trabalho de Mendel, legivel hoje, tantos annos apoz sua publicação, sem que seja necessario alteral-o em nada. E' com toda a justiça que a sciencia dos cruzamentos é hoje conhecida com o nome de Mendelismo.

O estudo da hereditariedade, cuja base é o Mendelismo, constitue hoje um dos mais solidos e grandiosos capitulos 
da biologia. Não seria possivel, nem é intenção minha tratar aqui de suas varias partes. A mais evidente prova de quanto seria isso impraticavel está em que esse assumpto foi por mim estudado o anno passado em uma serie de 11 conferencias, e ninguem mais do que eu reconhece o quanto foi elementar e insufficiente este curso.

$\mathrm{O}$ caracter deductivo de Mendelismo obriga-me a ficar nos seus primeiros theoremas. Podereis julgar perfeitamente a situação si imaginardes um geometra que pretendesse demonstrar o theorema de Pythagoras a um leigo em geometria. Seria necessario passar por uma cadeia de theoremas até attingir aquelle. Não devemos pois ter a illusão de que uma conferencia nos porá ao nivel do desenvolvimento a que chegou hoje a Genetica. Muitas affirmações aqui feitas, poderão parecer destituidas de base scientifica solida, principalmente porque não disponho de tempo sufficiente para demonstral-as. Todos os hybridisadores que precederam Mendel procuraram resolver o problema cruzando especies tão afastadas quanto possivel. Nestas condições as differenças que separam os dois typos cruzados, sendo muito numerosas, resultam, nas gerações oriundas de taes cruzamentos, tão grande numero de typos que se torna impossivel a demonstração do que quer que seja.

As experiencias de Mendel foram feitas durante 8 annos, no jardim do Mosteiro dos Augustinhos de Brünn, (Königskloster) do qual foi mais tarde prior. A intuição genial que o guiou em seus cruzamentos, foi a seguinte: cruzar duas raças eguaes em tudo menos em uma coisa, em seguida cruzar duas raças eguaes em tudo menos em duas coisas e assim successivamente. Nessas condições o problema se apresenta em seus casos mais simples e decoberta a lei que o rege, é facil deduzir o que se ha de passsar nos casos progressivamente mais complicados, como foi perfeitamente demonstrado por Mendel. Assim, por exemplo, cruzou elle ervilhas verdes com amarellas (Fig. 1). A geração inicial é designada symbolicamente por P.; os descendentes, que chamaremos $F$ 1, apresentam-se todos amarellos (uniformidade ou isotypia dos $F$ 1). 0 caracter amarello que apparentemente destruio o caracter verde é chamado dominante; o verde, recissivo. Cruzemos agora entre si esses F 1, que são amarellos mas filhos de amarello com verde; os F 2 resultantes serão, desde que tenhamos feito uma estatistica em escala conveniente, 3/4 
amarellos e $1 / 4$ verdes. Vemos pois que verde não havia sido destruido, Mendel mostrou ainda que estes verdes são puros, isto é, cruzados entre si dão indefinidamente

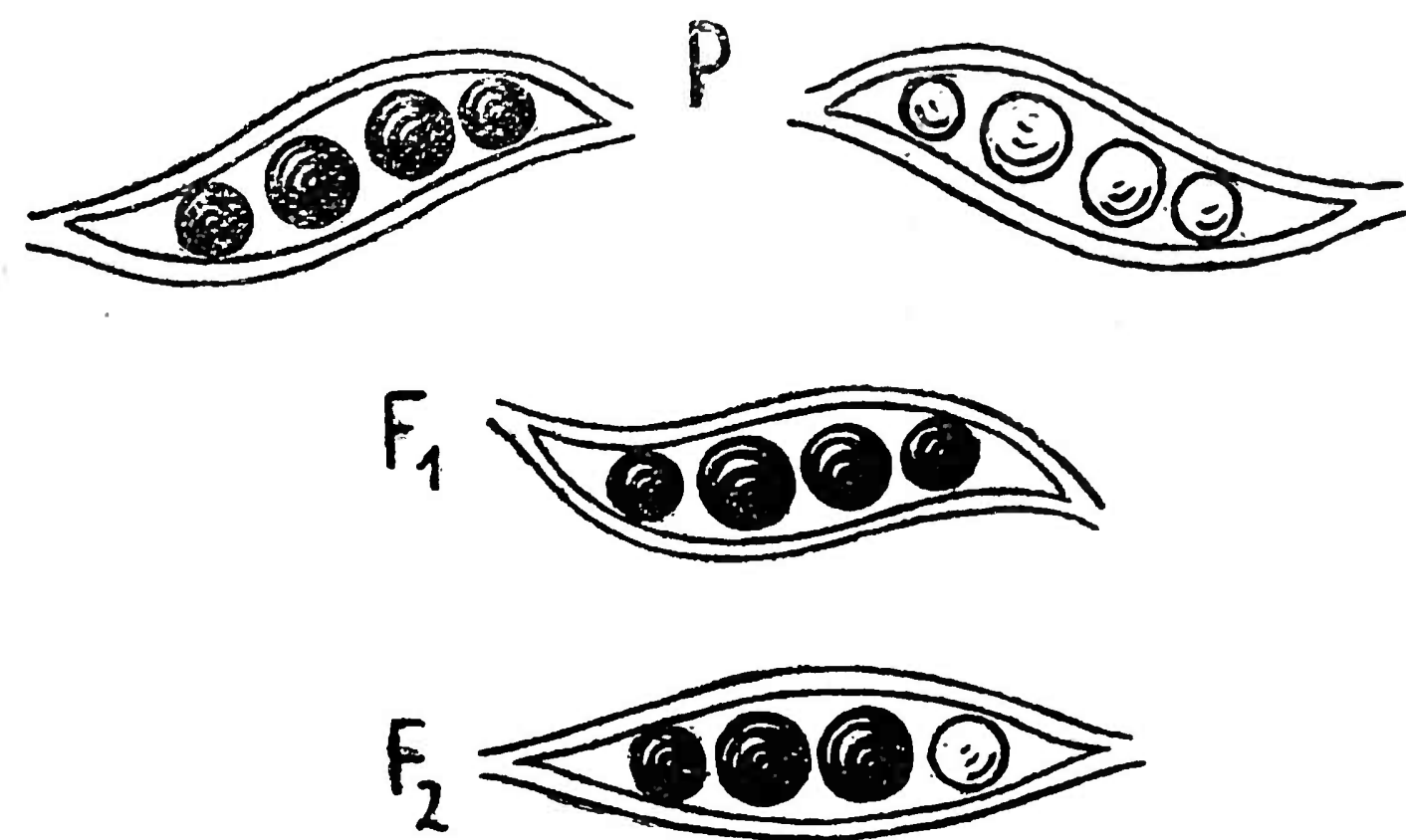

FIG. 1 (segundo Morgan)

Cruzamento entre ervilhas amarellas (em preto na fig.) e verdes (em branco na fig.)

verdes. Dos amarellos $1 / 3$ são puros, isto é, dão uma descendencia constante e $2 / 3$ são hybridos pois repetem em F 3 a disjuncção observada em $F 2$ ou seja, cruzados entre si dão $1 / 4$ verdes e $3 / 4$ amarellos. Este facto fundamental, isto é, o reapparecimento em $F 2$ dos typos puros de que partimos constitue a lei $d a$ disjuncção, divergencia ou segregação. Por mais que continuemos os cruzamentos, os resultados comportar-se-ão sempre como acabamos de vêr.

Como explicar tal resultado? Aqui se manifesta a extraordinaria perspicacia de Mendel de um modo admiravel, pela creação da theoria da pureza dos gametos, segundo a qual emquánto possuem as cellulas componentes do corpo (somaticas) de um vegetal ou animal dois factores para cada caracter, as cellulas reproductoras (germinativas) só possuem um. Si designarmos nos exemplos precedentes (Fig. 2) os factores para as cores verde e amarello por v e A, teremos, que o cruzamento de A com v produz um individuo em cujas cellulas coexistirão os dois factores, por isso chamado individuo hybrido, mas suas cellulas reproductoras só terão o factor $\mathrm{A}$ ou o factor $\mathrm{v}$, logo as cellulas reproductoras, ainda mesmo as de um hybrido são puras. Acceita tal hypothese é facil calcular o que se deverá dar 
em F 2. As cellulas sexuaes masculinas dos $F 1$ serão A e $v$ (em igual numero) e da mesma forma para as femininas. Se admittirmos que a fećundação se dá ao acaso, teremos finalmente $1 \mathrm{AA}$, (amarello puro), $2 \mathrm{Av}$ (amarellos hybridos) e $1 \mathrm{vv}$ (verde puro).

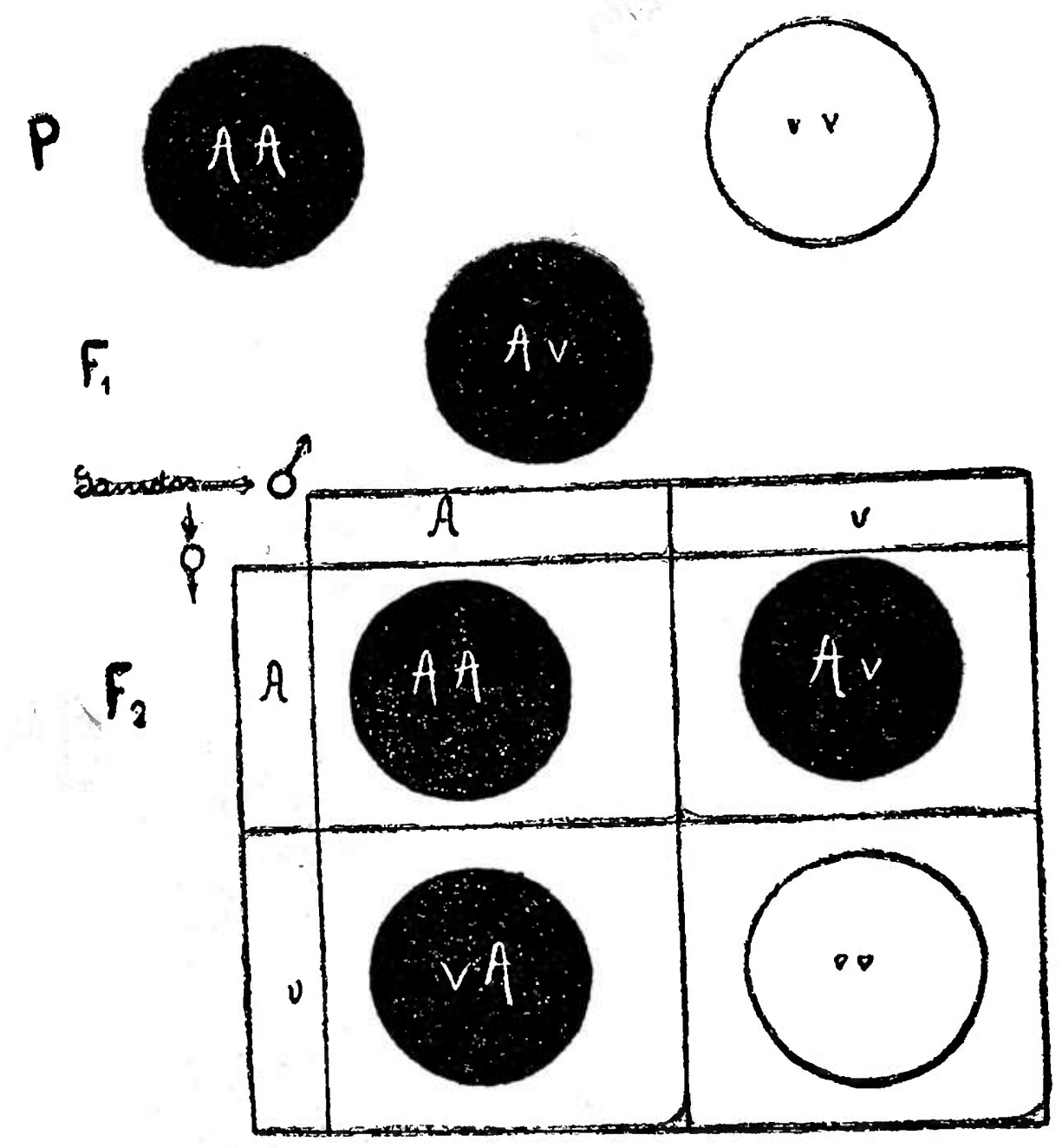

FIG. 2

Interpretação dos resultados dos cruzamentos indicados na fig. 1.

Seja-me permittido chamar vossa attenção para o seguinte: no caso de existir dominancia, como nas ervilhas, individuos com o mesmo aspecto podem ter constituições hereditarias differentes. Assim haverá ervilhas amarellas puras (AA) e amarellas hybridas (Av). Explicaremos assim porque motivo embora geralmente os filhos se pareçam com os paes, em certos casos, differenças são observadas; pois um amarello hybrido póde, cruzado com outro amarello hybrido dar individuos verdes. E' pois necessario distinguir o aspecto apresentado pelo individuo (phenotypo) de sua constituição hereditaria (genotypo); um mesmo phenotypo podendo corrresponder a varios genotypos (AA, Av). Dizem-se puros ou homozigotos para um determinado caracter os individuos que possuem dois 
factores iguaes para este caracter (AA, por exemplo) e hybridos ou heterozigotes os que apresentam dois factores differentes para o referido caracter (Av, por exemplo).

Esta interpretação theorica de Mendel, unica capaz de explicar os resultados constatados poude, por assim dizer, ser objectivamente confirmada mais tarde por outros pesquizadores, em material apropriado. Assim, se cruzarmos Mirabilis jalapa alba com Mirabilis jalapa rubra (Fig. 3) obtermos em F 1 Mirabilis jalapa rosea; falta pois aqui a dominancia, sendo os F 1 intermediarios entre os P. Cruzando agora estes $\mathrm{F} 1$, entre si teremos em F 2, 1 rubra, 2 rosea, 1 alba. Tal resultado deve ser interpretado de accordo com a hypothese de que $M$. jalapa rosea formou cellu-

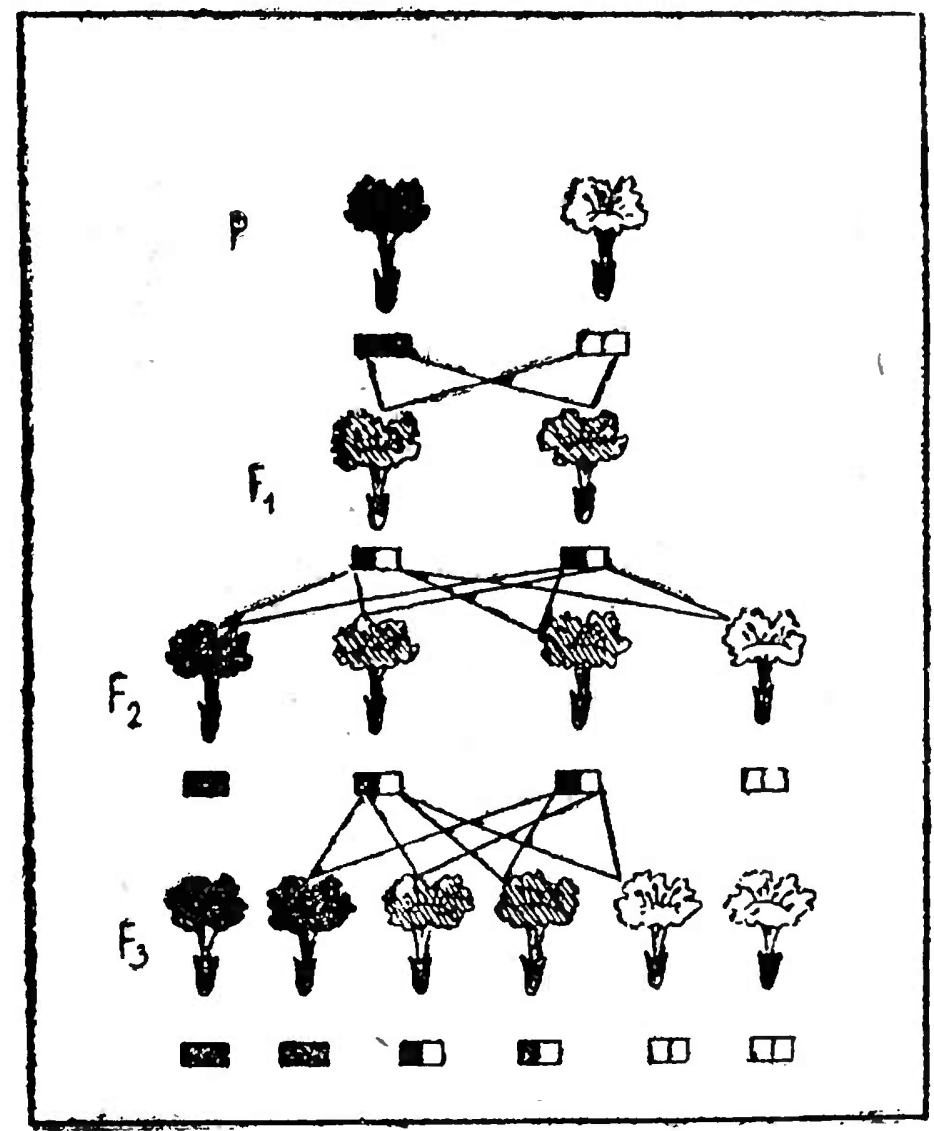

FIG. 3

Cruzamento entre Mirabilis jalapa rubra (em preto na fig.) e Mirabilis jalapa alba (em branco na fig.). Os rectangulos abaixo das flores mostram a natureza dos 2 factores allelomorphos para a cór, existentes nas cellulas somaticas; os quadrados constituintes dos rectangulos, representam os gametos $e$ as linhas que os unem, os resultados dos cruzamentos.

las sexuaes com o factor rubra e outras com factor alba. A fecundação dando-se segundo as leis do acaso o resultado acima podia ser previsto.

A analyse de um caso simples como o das ervilhas é todavia sufficiente para destruir pretensas leis da heredita- 
riedade que ainda hoje são, por alguns pesquizadores extranhos aos documentos positivos obtidos pela genetica, levados a serio. Tal é o caso relativamente as leis de Galton. Falta-nos tempo para analysal-as detidamiente e mostrar em particular porque, usando Galton como Mendel, o methodo estatistico,. chegou este a penetrar o verdadeiro mecanismo da transmissão dos factores, emquanto assentava Galton as celebres duas leis que hoje sabemos serem erradas. Chamarei apenas vossa attenção para o seguinte facto: de accordo com Galton, cada descendente é influenciado por todos os seu antepassados e tanto mais intensa é essa influencia quanto mais proximos são os ascendentes. Assim, os paes influem como $1 / 2$, os quatro avós como $1 / 4$, os oito bisavós como $1 / 8$ e assim successivamente. Isto posto, uma ervilha amarella hybrida, isto é, contendo factores para amarello e para verde nunca poderia dar descendentes verdes puros, nem amarellos puros, pois os verdes puros não soffreriam mais a influencia dos antepassados amarellos, escapando os amarellos puros a dos verdes. Ora, o cruzamento por nós estudado mostra que em F 2 ha $1 / 4$ de verdes puros e 1/4 de amarellos puros. Deante de taes resultados objectivos - existencia de puros derivados de hybridos - resultado confirmado, como adeante veremos, para numerosos caracteres, de vegetaes e animaes, não nos é mais permittido tomar em consideração as referidas leis de Galton.

Consideremos agora o caso em que os individuos cruzados differem por 2 caracteres. Vejamos qual será o resultado do cruzamento entre ervilhas amarellas e de contorno liso com outras verdes e de contorno anguloso. Em F 1 todos os descendentes serão amarellos - lisos. Verde e rugoso são pois caracteres recessivos. Os F 1 cruzados entre si dão, em média, em F 2: 9 amarellos lisos, 3 amarellos rugosos, 3 verdes lisos e 1 verde rugoso (fig. 4 ).

Como explicar que em F 2 appareçam não só individuos iguaes aos $\mathrm{P}$, isto é, amarellos-lisos e verdes rugosos, mas ainda outros que apresentam aquelles caracteres combinados de modos diversos, isto é, amarellos rugosos e verdes
lisos?

Já vimos que as cellulas sexuaes só possuem um dos dois factores existentes nas cellulas somaticas e que condicionam um mesmo caracter. (factores allelomorphos). que se formaram nos F 1 não só cellulas sexuaes identicas 
ás existentes nos $\mathrm{P}$, isto é, com factores para amarello liso e verde rugoso, mas ainda outras que receberam do patrimonio hereditario paterno um factor (amarello, por exemplo) e do patrimonio hereditario materno o outro factor

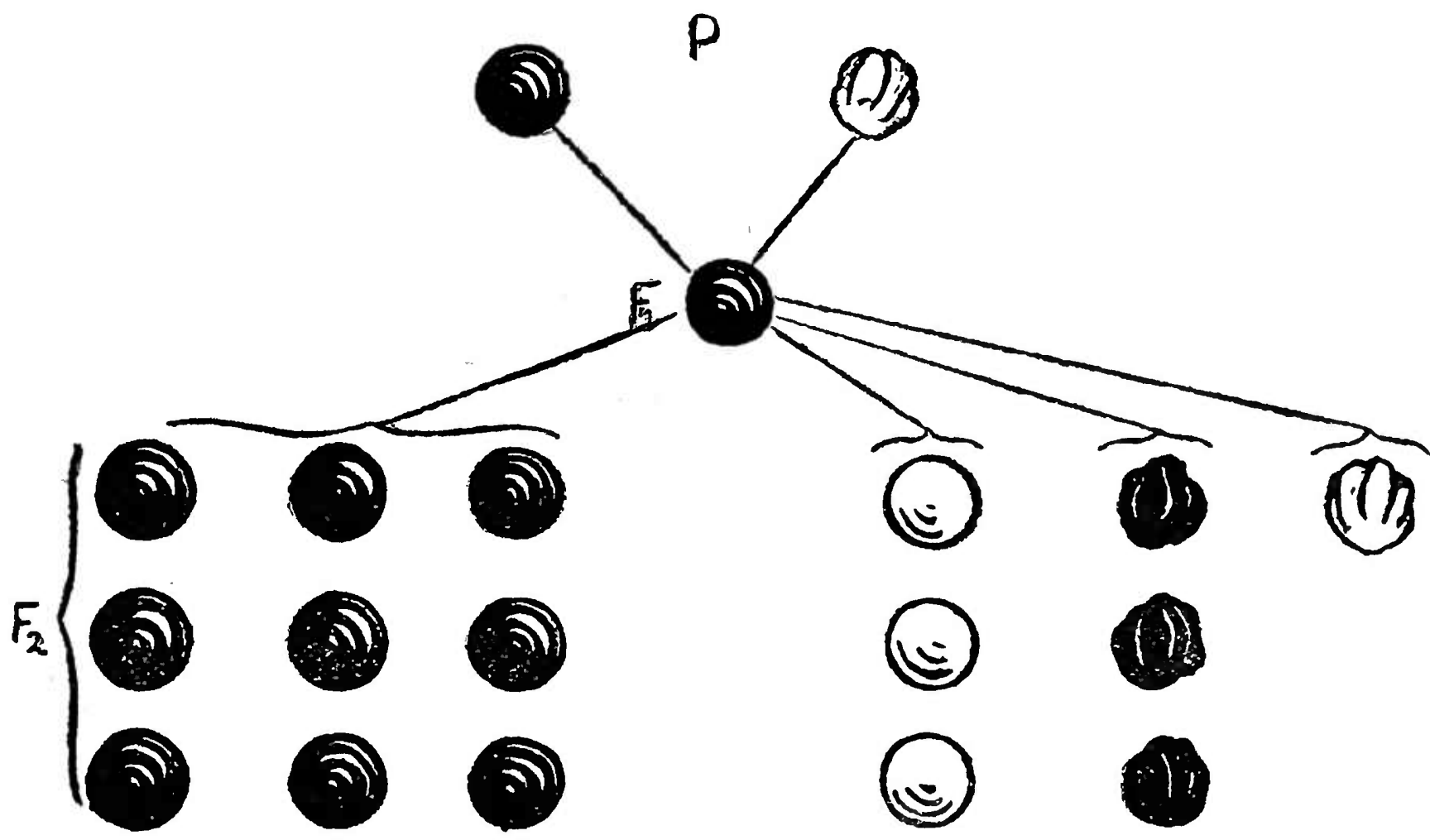

FIG. 4 (segundo Morgan)

Cruzamento entre ervilhas amarellas-lisas e verdes-rugosas.

(rugoso, por exemplo). Dahi a conclusão de que o patrimonio hereditario do $F 1$ que resultou da fecundação de um gameto (cellula sexual) com os factores amarello-liso por outro gameto com os factores verde-rugoso, formou gametos amarello-liso, verde-rugoso e tambem e em igual numero gametos verde-liso e amarello-rugoso (fig. 5). A conclusão é que verde, amarello, liso e rugoso podem se separar e depois se unir segundo todas as combinações possiveis, satisfeita apenas a condição de receber cada gameto um factor para cada caracter.

Em conclusão: um gameto para verde rủgoso foi buscar o factor côr no patrimonio hereditario de um antepassado e o factor forma do grão no outro, logo: o patrimonio hereditario é formado de partes isolaveis uma das outras, e descontinuo, e não póde ser considerado como um todo indivisivel.

E'-nos absolutamente indispensavel analysar mais detidamente este resultado, pois só assim poderemos com- 
prehender o facto éssencial demonstrado por Mendel e que rege toda a hereditariedade: a segregaçấo independente dos factores. Commumente ouvimos dizer que o patrimonio hereditario deve ser considerado como um TODO indi-

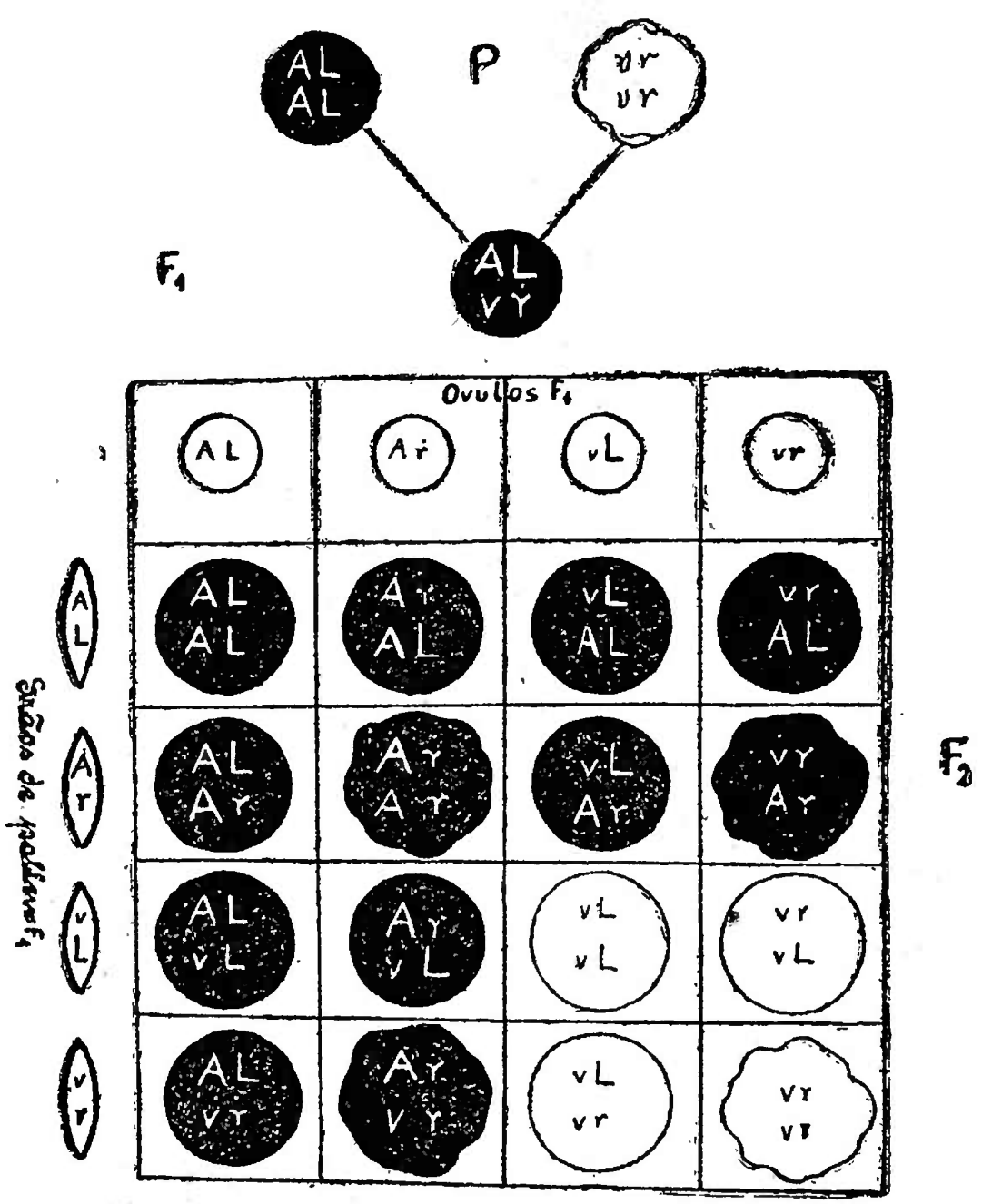

FIG. 5

Interpretação dos resultados dos cruzamentos indicados na fig. 4.

vizivel, e que a concepção de Weissmann, de que existem neste patrimonio numerorosas particulas correspondentes a outros tantos caracteres, é uma ressurreição da velha theoria da preformação, theoria que admittia estar o individuo já completamente constituido em miniatura, no ovulo (ovistas) ou no espermatozoide (espermistas). Cada particula seria pois, representante de uma futura parte do indi-
viduo.

As criticas justas feitas aos excessos de Weissmann, foram sufficientes para mostrar a fragilidade de muitas de pheticoncepções, todavia não annullaram a noção quasi propatrimonio hereditario em que foi feita, da existencia no 
existencia objectivamente provada pelas experiencias de di e poly-hybridismo. Estamos aqui deante de um dos capitulos mais curiosos da biologia contemporanea, no que respeita a mentalidade de certos biologistas modernos. Apesar dos resultados do di e poly-hybridismo só serem interpretaveis como acabamos de mostrar, em termos da concepção da discontinuidade do patrimonio hereditario, encontramos em trabalhos actuaes, a negação daquella discontinuidade, sem que os auctores desta negação possam dar de sua concepção outra justificação afóra o ser, para elles, o patrimonio hereditario um todo, artigo de fé.

Voltemos aos resultados do di-hybridismo:

As proporções numericas de F $2(9,3,3,1)$ são facilmente comprehensiveis se admittirmos que os 4 typos de gametos que se podem formar ( $\mathrm{AL}, \mathrm{Ar}, \mathrm{vL}, \mathrm{vr}$ ) se formam segundo as leis do acaso, isto é, teem igual probabilidade de se formar, havendo pois em media 1 de cada typo. Se nos dermos ao trabalho de verificar quaes são os resultados do cruzamento, concluiremos que aquelles 4 typos de gametos masculinos fecundando os mesmos 4 typos de gametes femininos dão em resultado 16 individuos, (fig. 5) apresentando os 4 phenotypos citados e nas proporçôes acima ditas, correspondentes a 9 genotypos.

Outro resultado interessante de di-hybridismo, que logo salta aos olhos, é a possibilidade do apparecimento de novas raças estaveis, isto é, puras, taes como as ervilhas verde lisas e amarello-rugosas.

Os resultados do tri e de um modo geral os do polyhybridismo são da mesma ordem que os de di-hybridismo, mas não dispomos aqui de tempo para analysal-os mais longamente. Guardemos apenas que já no tri-hybridismo haverá 27 individuos tri dominantes, 3 grupos de 9 individuos bi-dominantes, 3 grupos de 3 individuos bi-dominantes e 1 só individuo tri-recessivo (isto em F 2). Logo o typo tri-recessivo só reapparece uma vez em 64 individuos. $\mathrm{Si}$ os individuos differirem por 10 caracteres, o typo 10 vezes recessivo só reapparecerá uma vez em 1.048.576 individuos, o que explica porque estas leis simples só foram descobertas quando o cruzamento foi realisado em individuos que só differiam entre si por poucos caracteres. Torna-se facil comprehendermos agora a razão pela qual sempre que as differenças entre os individuos são muito numerosas, como acontece no cruzamento entre especies dif- 
ferentes, tem-se á primeira vista a impressão de que as leis de Mendel não se applicam.

$\mathrm{Si}$ em vez de dominancia e recessividade os caracteres dos hybridos forem intermediarios entre os dos P., então os 2 typos iniciaes só reapparecerão um numero tão escasso de vezes quanto os recessivos no exemplo acima. Parecerá ainda mais evidente do que para os anteriores a inapplicabilidade das leis a taes casos, mas sempre que a estatistica poude ser feita em escala apropriada verificou-se que os resultados eram absolutamente comparaveis com os que podiam ser previstos de accordo com aquellas leis.

As leis de Mendel foram como acima dissemos, confirmadas para toda a sorte de caracteres dos vegetaes: forma e côr das flores, forma e côr dos grãos, seu theor em amido ou assucar, floração annual ou bi-annual, comprimento de caule, dimensões dos fructos, etc.; e nos animaes: pigmento dos pellos, plumas, pelle, iris, presença de chifres, formas de crista, modo de crescimento e implantação dos pellos, fertilidade, fecundidade, ausencia de asas, etc. etc.. homem.

Uma critica feita a essas leis era a de que a herança Mendeliana só se applicava a caracteres de importancia secundaria, taes como: côr, forma, tamanho, isto é, a caracteres ornamentaes. A razão porem, de terem sido taes leis verificadas primeiramente a proposito desses caracteres, resulta de serem elles mais accessiveis de que quaesquer outros a estudos desta natureza. Hoje, porem, tal critica não tem mais razão de ser, pois foi demonstrado que a ausencia de olhos, a longevidade, a ausencia de azas, varias doenças, das quaes algumas extremamente graves, se comportam como caracteres mendelianos.

Exceptuados certos raros e pouco importantes como por exemplo os da herança dita cytoplasmica, observada em alguns vegetaes, pode-se admittir que toda a hereditariedade obedece aos principios estabelecidos por Mendel.

$E^{\prime}$ indispensavel accentuar que nem sempre as cousas se passam de um modo simples como nos exemplos estudados. Se dispuzessemos de mais tempo analysariamos outros casos em que interveem factores de intensidade, condicionaes, transmutadores, de repartição, complementares, etc.; casos esses em que as leis são verificadas, mas com modificações devidas a effeitos diversos condicionados por factores que teem um comportamento particular. 
De todos esses casos particulares ha um que por sua importancia para a especie humana merece referencia especial. Refire-me á côr da pelle. Como é sabido tal caracter, dado como exemplo classico de herança mixta, não parece obedecer ás leis de Mendel, pois 2 mulatos casados entre si não teem em media; para cada 4 filhos, 1 branco, 1 negro e 2 mulatos; o que se deveria dar, si esse caso fosse analogo ao do M. jalapa. F alta, pois, a volta aos typos iniciaes em F 2, volta caracteristica de Mendelismo. Coube aos Davenport demonstrar que este caso tambem deve ser. interpretado em termos da linguagem Mendeliana e como um caso de polymeria. Lang assim designou caracteres devidos não á acção de um só par de factores, mas sim á de numerosos pares. Assim, se o caracter fôr devido a 3 pares de factores sommando seus effeitos (AAAAAA, sendo o individuo preto; aaaaaa, sendo branco) termos em F $1 \mathrm{mu}-$ latos AAAaaa) e em F 2 graças á formação de gametos AAA,AAa,Aaa,aaa, haverá em media em cada 64 individuos 1 preto puro, 6 quasi pretos, 15 mulatos escuros, 20 mulatos, 15 mulatos claros, 6 quasi brancos e 1 branco puro (fig. 6). E' facil de se comprehender, que, se o caracter for condicionado por numero muito maior de pares de factores, os typos extremos serão cada vez mais raros e os mulatos de F 2 cada vez mais numerosos. Ora, como os Davenport mostraram confirmado por Roquette Pinto) mulatos podem ter em casos muito raros, filhos brancos ou pretos e muito frequentemente observamos mulatos terem filhos mais claros ou mais escuros do que elles proprios, resultado que qualquer um de nós pode facilmente comprovar. Taes factos são absolutamente incompativeis com a concepção da herança mixta, que obrigaria os filhos a terem sempre uma côr de pelle intermediaria entre a de seus paes.

Os trabalhos modernos de cytologia vieram trazer uma inesperada e extraordinaria prova em favor do Mendelismo. Vimos que na hypothese de Mendel as cellulas somaticas teem 2 factores para cada caracter e as cellulas sexuaes 1 só. Se analysarmos as cellulas sexuaes comparativamente com as cellulas somaticas veremos que ha 1 elemento que existe em dose dupla nestas e singela naquellas. Quando as cellulas componentes do nosso organismo entram em divisão, a substancia caracteristica do nucleo, chamada chromatina, se fragmenta em um numero determinado de pedacos, designados chromosomas. Pois bem, si contarmos os chromosomas veremos que o numero delles, que é fixo para 
cada especie animal ou vegetal, é duas vezes maior nas cellulas somaticas do que nas sexuaes. Dahi a idea de localisar nas chromosomas os factores Mendelianos. E'-me infelizmente impossivel analysar comvosco esta extraordina-

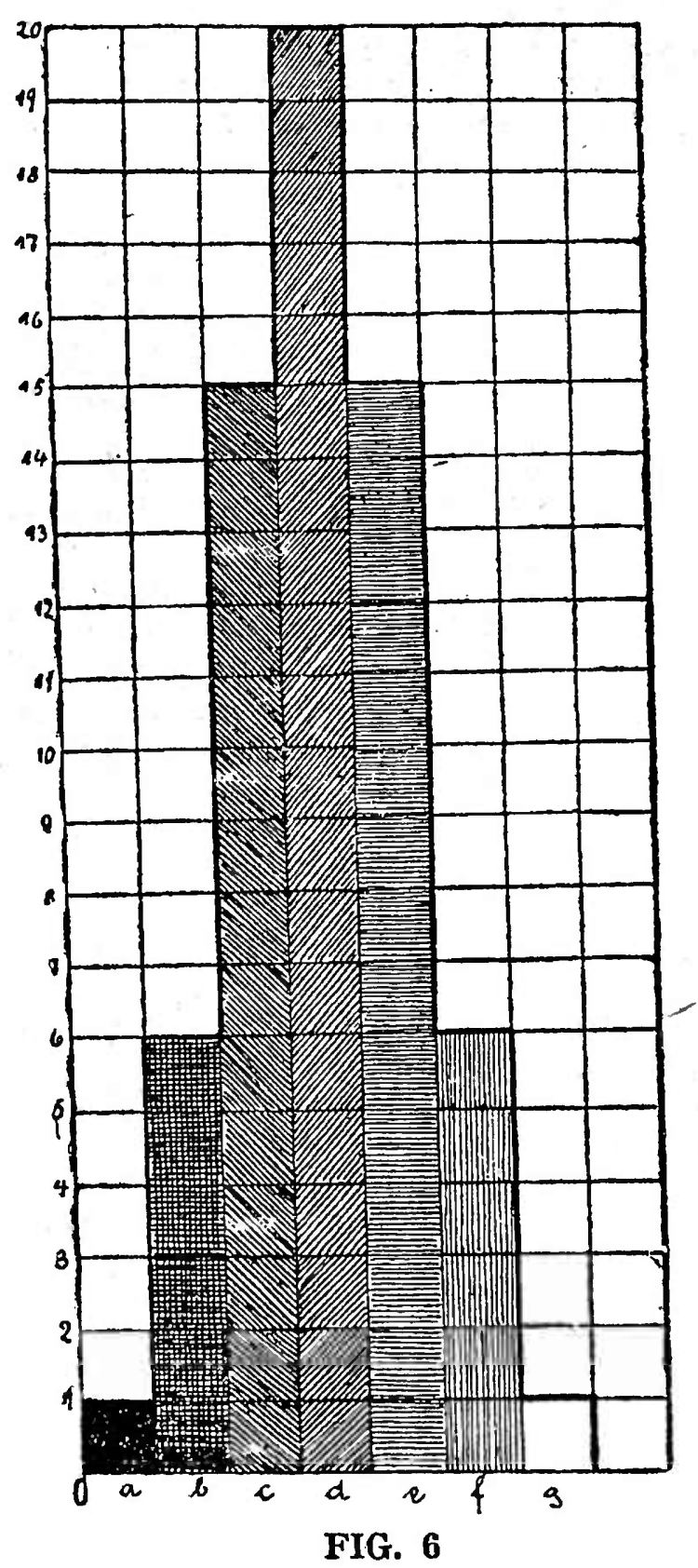

Polymeria - Em ordenadas: n. $^{\circ}$ de individuos de cada classe, em abcissas: classes de individuos. a e $\mathrm{g}$ constituem as classes dos individuas puros $(\mathrm{a}=$ pretos puros, $\mathrm{g}=$ brancos puros).

ria theoria, uma das mais brilhantes conquistas da biologia contemporanea. Suas provas são tão numerosas e demonstrativas que a possibilidade de seu abandono se mostra muito pouco provavel. Seria injustiça deixar de citar os trabalhos de Blakeslee e Belling na Datura e particularmente os de Morgan na mosca Drosophila melanogaster que chegam aos mais espantosos resultados já obtidos em biologia. Jul- 
gareis do gráu de penetração do trabalho de Morgan quando souberdes que a elle se deve um mappa com a distribuição de cerca de 400 pares de factores Mendelianos por elle estudados nesta mosca. O mappa indica não só a ordem de situação dos factores nos chromosomas, mas ainda a distancia relativa existente entre elles. Sua obtenção representa o resultado de longos annos de multiplas, pacientes e engenhosas experiencias que permittiram seu estabelecimento por via experimental indirecta.

Para que possaes ter uma idéa das luzes que a theoria chromosomica veio trazer á resolução de certos problemas de, hereditariedade, tomarei o exemplo da herança ligada ao sexo (Sex-linked). Para entender este problema deveis ter presente, que em certas especies o macho se distingue da femea por ter menos um chromosoma de que ella. Na especie humana, segundo Winiwater e Oguma, haveria 47 chromosomas no homem e 48 na mulher. Como é facil de se demonstrar que os chromosomas formam pares, no macho haverá um chromosoma sem parceiro, geralmente chamado $\mathrm{X}$, ou heterochromosoma, ao passo que na femea encontraremos 2 delles. $O$ macho será pois $\mathrm{X} O$; e a femea XX. Em certas especies, como na Drosophila (e na especie humana, segundo Painter que admitte 48 chromosomas tanto no homem como na mulher) ha no macho um parceiro para o chromosoma X. E' um pequeno chromosoma designado $\mathrm{Y}$ e que a experiencia prova não transportar factores hereditarios, tudo se passando pois como se tal chromosoma não existisse e como se o macho fosse XO. Finalmente em outros animaes observa-se uma inversão de typos de chromosomas sexuaes sendo a femea $\mathrm{ZZ}$ e o macho ZW Nas especies onde nenhuma differença chromosomica se observa entre os dois sexos ha indicios seguros de que uma differença physiologica correspondente a que acabamos de descrever está presente.

Um simples golpe de vista nas figuras numeros 7 e 8 permitte-nos comprehender os resultados do cruzamento entre Drosophilas de olhos vermelhos $\mathrm{x}$ olhos brancos. Como se vê os resultados de F 1 e F 2 differem profundamente segundo o sentido do crusamento não sendo portanto aqui indifferente, como succede para os caracteres Mendelianos communs, partirmos do crusamento macho vermelho $x$ femea branca ou macho branco $x$ femea vermelha. Os resultados de $F 1$ e $F 2$ são facilmente interpretaveis se admittirmos, que o factor para a cór dos olhos é transpor- 
tado pelo heterochromosoma, sendo vermelho dominante e branco recessivo. Convem assignalar que fóra dessa interpretação é absolutamente impossivel dar conta de tão curiosos resultados.

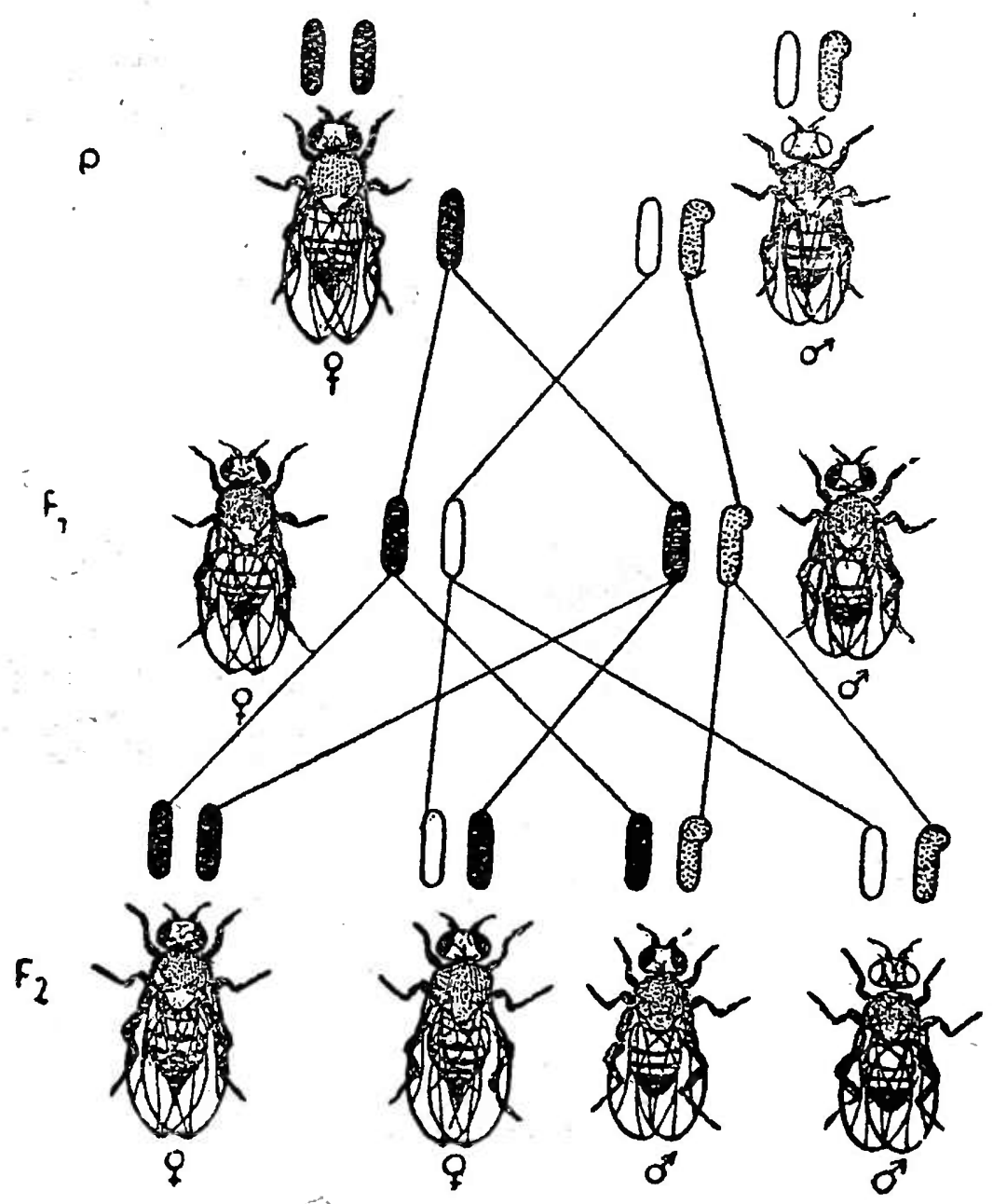

FIG. 7 (segundo Morgan)

Cruzamento entre D. melanogaster femea de olhos vermelhos e $D$. m. macho de olhos brancos; em F1, femeas e machos vermelhos; em F2, todas as femeas vermelhas (50\% puras, $50 \%$ hybridas), $50 \%$ de machos brancos, $50 \%$ vermelhos.

As ellipes ao lado das moscas representam os heterochromosomas, transportadores dos factores vermelho (em preto) ou branco (em

O chromosoma $\mathrm{Y}$ do macho em pontilhado, não transporta genes. 0 macho possuindo apenas 1 chromosoma $x$ não póde ser hybrido.

No homem, certas doenças (hemophilia - fig. 9), daltonismo, nyctemeralopia, etc.) se comportam da mesma maneira que a distribuição da côr dos olhos na Drosophila. A hemophilia, doença essencialmente caracterisada por mamente graves quaesquer especies de ferimentos, sabe- 
mos ser hoje uma doença ligada ao sexo. 0 exame do quadro annexo (Fig. 9) mostra-nos porque é a doença muito mais frequente nos homem, comportando-se geralmente como se fosse transmittida pelas mulheres.

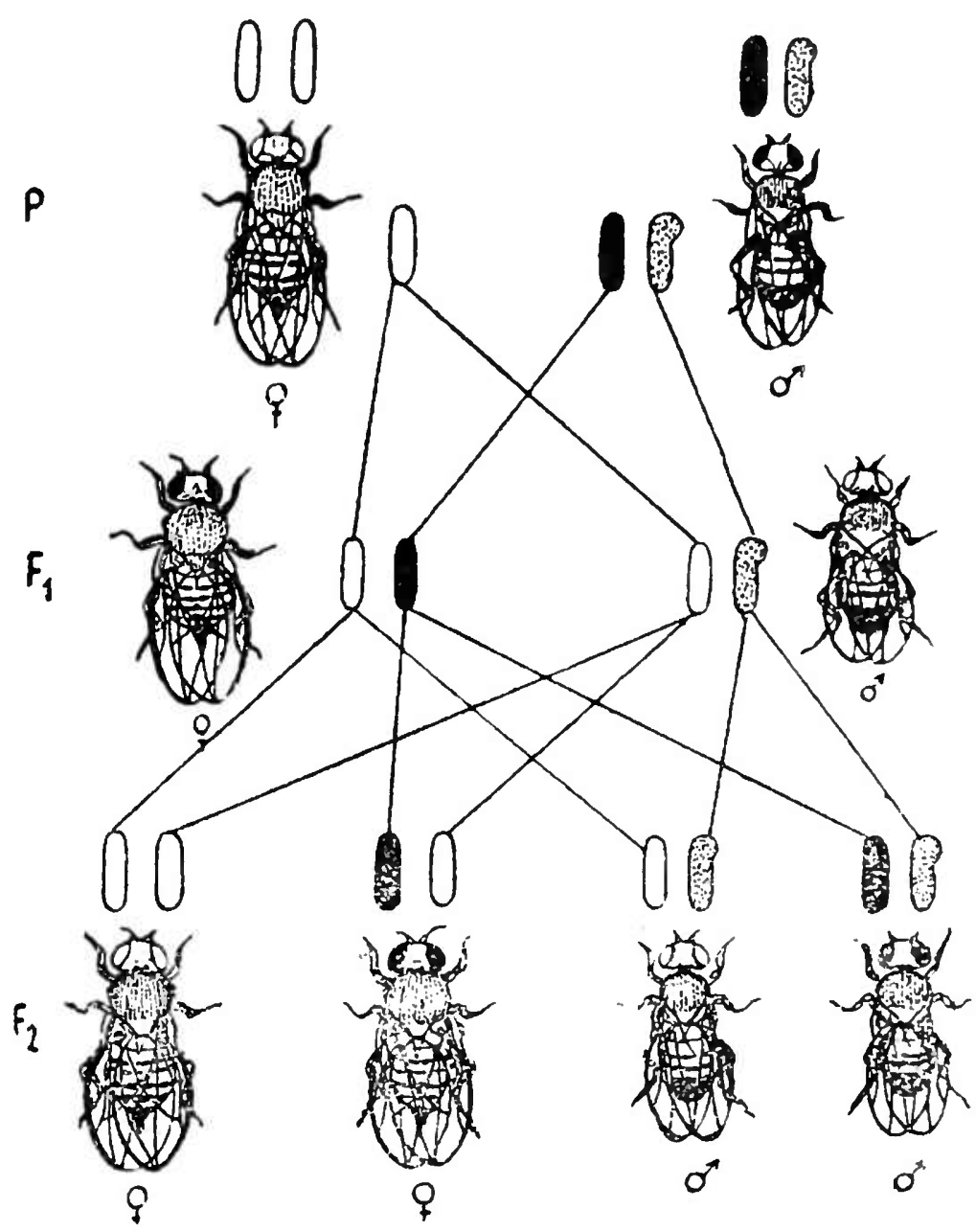

FIG. 8 (segundo Morgan)

Cruzamento inverso do representado na fig. 7.

Em F1 as femeas são vermelhas (hybridas) e os machos brancos. Em F2 metade das femeas vermelhas (hybridas), metade brancas; metade dos machos brancos, metade vermelhos.

Serão as leis de Mendel passiveis de applicação ao homem? E' o de que hoje ninguem mais póde duvidar, particularmente depois dos trabalhos de Fischer. Difficillimo é este estudo, e isto pelas seguintes razões: $10^{\circ}$ lentidão com que o homem se desenvolve, pois de Christo até hoje passaram proximamente 60 gerações pela terra, quando tal numero póde ser obtido em menos de 3 annos na Drosophila, de 2 mezes nos Paramecios. 2..$^{\circ}$ pouca prolicifidade do homem. $3 .^{\circ}$ impossibilidade de fazermos nelle experiencias de genetica, só nos sendo possivel praticar observações. Póde-se todavia affirmar pelo numero enorme de dados colhidos, que aqui como nos demais domi- 
nios da biologia geral as leis da hereditariedade são as mesmas para todos os seres vivos.

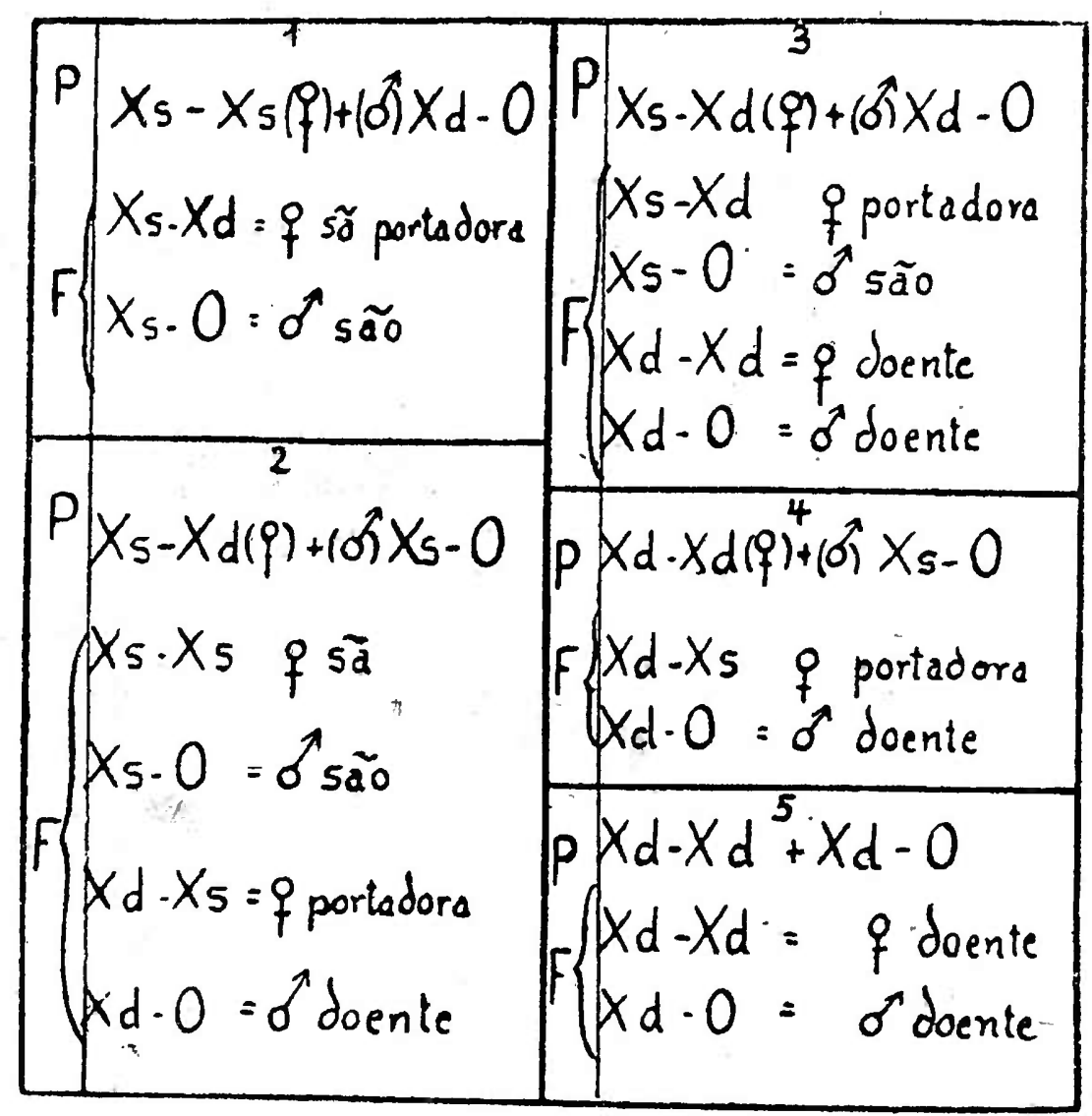

FIG. 9 (segundo Guyénot)

Herança da hemophilia no homem.

$\mathbf{X}$, representa o heterochromosoma, unico no homem, duplo na

Xs, é o heterochromosoma portador do factor para normalidade (dominante).

Xd, é o heterochromosoma portador do factor para a doença (recessivo).

Em 3 vemos a explicação da chamada herança paterna (caracter passando do pae para os filhos). Em 4 vemos a explicação da chamada herança materna e cruzada (caracter passando da mãe para
o filho).

Seguem, a titulo de exemplo, alem da côr da pelle e da hemophilia já estudado, alguns caracteres examinados sob esse ponto de vista:

Caracteres

Cabellos

Côr dos olhos

\section{Dominantes}

crespos

escuros

escuros

\section{Recessiúos}

lisos (1)

claros

claros

(1) Os lisos dos chinezes seriam dominantes.

(2) Por vezes inversão com a edade. 


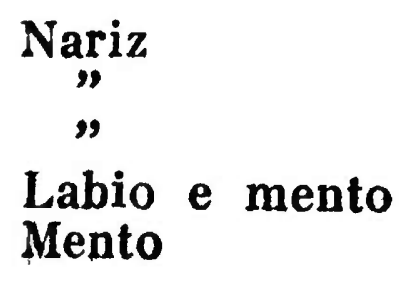

aquilino
achatado
arrebitado
espesso
prognata

Caracteres psychologicos

Aptidão intellectual

\author{
commum \\ ," \\ 9) \\ 9) \\ commum (3)
}
fleugmatico
energico
talento musical
commum
muito grande
muito pequena

Caracteres pathologicos (doenças familiares, malformações, etc.) estatura

pigmentação

Pellos
Ölhos

Ouvido

Doenças "nervosas

9

.8

Doenças mentaes

99

achondroplasia
normal
normal
albinismo parcial
calvice no homem
glaucoma
normal
normal
choréa de Huntington
normal
",
"
$\quad$,
psychose maniaco-
depressiva

normal

nanismo verdadeiro albinismo

normal

calvice na mulher

normal

retinite pigmentar surdi-mudez

normal

doença de Thomsen

paralysia agitante

epilepsia myoclonica

(Lundborgh)

idiotia

demencia precoce

normal

(3) Physionomia typo Habsbourg, Bourbon, Wittelsbach.

Claro está que os eugenistas não terão o direito, caso queiram realisar obra digna do nome de scientifica, de ignorar essas leis e as consequencias agradaveis ou não para os nossos preconceitos, dellas resultantes.

Assim, estamos hoje armados para nos pronunciarmos sobre as vantagens ou desvantagens da consaguinidade. Evidentemente não nos interessa aqui o ponto de vista ethico que cada qual resolverá como quizer. Mas, do ponto de vista biologico, podemos affirmar que quando taes uniões são realisadas entre individuos sãos, não portadores de factores recessivos para caracteres máos ou doenças, só po- 
dem dar os melhores resultados. Lembremo-nos de que este foi e é, o processo adoptado para isolar raças puras, usado pelos criadores, e que tantos resultados já tem fornecido. Com elle foram obtidos: cavallos de corrida, todas as raças de gado maximamente differenciadas, seja para o córte seja para a producção de leite, etc. etc.. - Si o individuo soffrer de doencas dominantes alguns de seus filhos serão fatalmente doentes, quer o casamento seja consaguineo, quer não o seja. Si finalmente o individuo fôr são mas portador de factores recessivos inconvenientes, os casamentos consaguineos, terão muito maior probabilidade de permittir o apparecimento de doentes ou defeituosos, mas esta probabilidade será a mesma si a esposa sã portadora e não consaguinea, fôr portadora em seu patrimonio hereditario deste mesmo factor.

Outra crença de varios eugenistas que tem infelizmente que ser abandonada é a de que um meio favoravel, boa alimentação, instrucção desenvolvida poderão influir sobre o patrimonio hereditario. Este é um dos aspectos do grande problema da transmissão dos caracteres adquiridos, hypothese de trabalho já apresentada por Lamark. Uma conferencia inteira não bastaria para desenvolver convenientemente semelhante these, mas aquelles que procurarem verificar o que se tem feito neste particular convencer-se-ão facilmente de que resultaram negativas todas as tentativas realisadas pelos mais diversos autores, nos mais diversos vegetaes e animaes no sentido de se obter a transmissão hereditaria dos caracteres adquiridos. Infelizmente nada sabemos ainda sobre os methodos que nos permittiriam destruir factores nocivos ou crear factores favoraveis; tudo demonstra a incrivel estabilidade dos factores hereditarios e a mesma impotencia em que estamos para crear novos factores beneficios, existe no que respeita á possibilidade da destruição de máos factores.

Um meio favoravel, no sentido mais lato, comprehendendo prophylaxia de toda a sorte de doenças contagiosas, boa alimentação, instrucção desenvolvida, é utilissimo para o individuo, e taes praticas só pódem merecer nessa inteira approvação, mas não seria justo que com isto se pretendesse modificar a especie, pois si um meio favoravel permitte a exteriorisação de caracteres que sem elle permaneceria latentes, este meio favoravel não cria nem destróe
factores hereditarios. 
Muito teria ainda que vos dizer si dispuzesse de tempo, particularmente sobre o modo de conciliar a theoria da evolução, unica concepção scientifica capaz de dar conta das innumeras relações anatomicas, embryologicas e physiologicas existentes entre os seres vivos a estabilidade inatingivel do patrimonio hereditario. Teriamos então que analysar os varios mecanismos propostos para explicar a evolução das especies e veriamos que nem a selecção natural, nem o uso ou não uso, nem a influencia de meio podem dar conta desta evolução. Só as mutações, cujo determinismo ainda nos escapa quasi completamente (pois certas pesquisas recentes deram resultados satisfactorios no sentido de determinar alterações dos factores e consequentcmente mutações) podem dar conta, embora de modo incompleto, dessa evolução.

Possam os biologistas de amanhã resolver o problema maximo da hereditariedade: o da creação de factores vantajosos e destruição dos nocivos. Por mais improvavel que se nos apresente hoje a resolução de tal questão, seria temeridade affirmar sua impossibilidade. Afóra os problcmas relativos a causas finaes, que escapam por sua natureza, a qualquer solução, scientifica ou outra, seria loucura pretender impôr limites ao futuro da sciencia. Os innumeros desmentidos que ella se tem apressado de dar áquelles que commetteram tal temeridade, devem nos servir de aviso e aconselhar-nos a nunca deseperarmos de suas possibilidades. 